\title{
Cause Analysis on Deficiency of Humanistic Education in English Teaching
}

\author{
Xin Wang \\ Liaoning Jidian Polytechnic, Dandong, 118009, China
}

Keywords: English teaching in colleges and universities, humanistic education, cause analysis

\begin{abstract}
In essence, the English teaching process in colleges and universities is a learning process of foreign language culture. Teachers in colleges and universities just use this learning process to penetrate humanistic education into English teaching and to integrate with it, so as to help students to improve their humanistic quality. Given this, this paper first gives a statement onto internal relations between English teaching in colleges and universities and humanistic \& spiritual education. Based on the special historical background of China at present, this paper discusses new requirements of new times for humanistic \& spiritual education in English teaching in Chinese colleges and universities. Moreover, an analysis is made onto relevant causes for deficiency of humanistic education in English teaching in Chinese colleges and universities. Based on current conditions and existing deficiencies of English teaching in Chinese colleges and universities, effective countermeasures and recommendations are proposed in this paper for the implementation of humanistic education in English teaching in Chinese colleges and universities, with certain positive reference to the promotion of teaching practices.
\end{abstract}

\section{Internal Relations between English Teaching in Colleges and Universities and Humanistic \& Spiritual Education}

In essence, humanistic spirit is served as an important ruler used to measure the level of civilization of a nation, a core of cultural spirit in the new times and even a core element of culture and personality of a nation. Humanistic spirit runs through people's thoughts, words and deeds. Moreover, humanistic spirit is served as people's belief, idea, value orientation, personality pattern and aesthetic taste as well as integrity of various spirits and values in the specific environment. Humanistic spirit is the internal motivation for overall development of people and also the external form of internal motivation for overall development of people. In addition, humanistic spirit is people oriented and people centered, which reflects people's value and dignity as well as cultural spirit of pursuing for perfection and free development of people.

According to Professor Xu Guozhang (an authority and famous language educator in China's English circle), language is a unique symbol system of human beings and also a carrier, which bears the history of a nation and contains cultural spirits of different nations. Language teaching can penetrate into the representation of linguistic symbols to explore its deep humanistic significance. Furthermore, Professor Xu Guozhang stresses that language teaching should always keep close connection with cultural education. As a kind of language teaching, college English teaching is also a kind of culture teaching, because "language is a mirror of culture, and all aspects of culture can be reflected in language".

Thus it can be seen that the exploration for humanity factors cannot be neglected in English teaching in colleges and universities. In English teaching in colleges and universities, we must enhance the exploration for and research on humanistic spirits concealed in language materials. Language teaching without humanistic spirit is just like a dead-alive person who loses its soul.

\section{Cause Analysis on Deficiency of Humanistic Education in English Teaching in Chinese Colleges and Universities}

(I) Deficiency of Humanistic Spirit of College Students 
Humanistic spirit is just a kind of quality letting people to surpass natural state and then step into civilized state. The formation of this quality relies on college students' emphasis on learning and cultivation of social values, language culture, good esthetic sentiment, basic moral principles and other aspects no matter in daily language learning activities or in various social practices. Thus it can be seen that humanistic quality and higher education come down in one continuous line and supplement each other. As an integral part of higher education, college English teaching undoubtedly should shoulder the important mission of improving humanistic quality education for students.

With gradual establishment of socialist economy and internationalization of economic development in China, however, various accompanying cultural concepts and social ideological trends rush into China one after another, resulting in unprecedented challenges to traditional social values in China. New social values have not been completely accepted and formed yet, social values and social ideological trends come in great numbers, thus directly leading to serious deficiency or even complete covering of social values of college students in China. Under such circumstance of numerous and complicated social values, cultural concepts and social ideological trends, it is difficult for college students who don't set foot in the society to adapt, thus triggering a series of psychological dislocation, unbalanced behavior, lost direction and other issues.

Then, the ideological trend of utilitarianism still runs wild like fierce floods and savage beasts in the entire college education process. As a result, contemporary college students loose their directions. Moreover, it is rather difficult for them to calm down to learn in a thoroughgoing manner. Unhealthy phenomena take place repeatedly, including cheating, blundering thought, academic fraud, extremely unfavorable style of study and seeking quick success and instant benefits. The balance of social justice begins to incline, and unprecedented adverse impacts are seen in social confidence crisis, seriously frustrating noble ideal and sentiment of college students. In some way, certainly, not humanistic spirit quality of all contemporary college students is weakened or lost. In a sense, just the existence of this phenomenon provides a wider development space and stage to broaden English teaching thoughts, carry forward humanistic spirits and enrich college English teaching theories in the contemporary college English teaching process.

(II) Covering of Humanistic Spirit of College English Teachers

Due to gradual penetration of utilitarianism and instrument rationality, especially corrosion and interference from professionalism and social utilitarianism in the present market, old and new social values and various ideals and faiths of college teachers in China collide with each other, resulting in diversified values or even the difficulty for them to find academic space belonging to themselves for a short while. In the teaching process, some teachers begin to slight over, being pure and lofty or indifferent, go after benefits and simply emphasize high official positions and riches. More seriously, some teachers even neglect close communication and exchange with students. Essentially, college teachers should be navigational lights for cultural knowledge development. Top-ranking education should give full play to wisdom and competence of students and teachers. A remarkable higher educator must move forward toward the development orientation of having both ability and political integrity and engaging in multiple aspects and become a wise man with personality charm and cultural character in such three aspects as morality, talent and learning. However, some college teachers till rest on relatively obsolete teaching concepts and fail to get rid of traditional and laggard teaching concepts, leading contemporary college students to lack certain learning motivation. Consequently, this negligence of humanistic spirit education directly leads to declining or weakening humanistic spirit education in college English teaching.

(III) Weakening of Humanistic Education due to Existence of Utilitarian Exam-oriented Education

It is not difficult to find from the existing college entrance examination system that some colleges or educational institutions are seriously affected by social utilitarianism thought, directly regarding indexes of entering a higher school as sole standard to measure educational level of a teacher and basically or even completely neglecting the cultivation of humanistic spirit and the improvement to humanistic quality for students. Due to impacts of utilitarian exam-oriented education for a long time, hence, the education of humanistic spirit in college English teaching fails 
to stress on meeting demands of social development for talents. Instead, such education examines and weighs educational value of humanistic spirit from the perspective of social utilitarianism. This path contrary to humanistic education will directly lead to instrumentalization of humanistic spirit education and regard humanistic education in college English education and teaching as a tool used to meet certain utility of people.

As everyone knows, no matter an individual person or a person in a group, once he lacks or even abandons humanistic spirit, then it is difficult to call him as a person. At present, China's college English educational pattern always regard education and teaching from the perspective of utilitarianism. No matter students or teachers unanimously think that humanistic spirit fails to generate substantial results, and they even think that humanistic spirit fails to bring about obvious social benefits. Consequently, they neglect to some extent tremendous social values in humanistic spirit in language teaching in the English teaching process. Therefore, to enhance the cultivation of college students' humanistic spirit in college English teaching process is priority among priorities of the present English teaching reform at present and even an effective path to adapt to new requirements of English teaching reform at present.

\section{Effective Countermeasures and Recommendations for Implementation of Humanistic Education in China's College English Teaching}

(I) Continuously improve educational background of teachers and promote teachers to be good at exploring for humanistic quality in college English teaching

A college English teacher must make continuous efforts to move forward, improve his/ her educational level and become model of his/ her students. Moreover, a college English teacher should become not only an education-oriented teacher but also a research-oriented teacher. On the one hand, a college English teacher should make continuous efforts to improve his/ her humanistic quality, lay emphasis on learning and practice, drive his/ her students to become useful persons by his/ her own progress, and actually realize the goal of teaching benefits teachers as well as students. On the other hand, we should strengthen the exploration for instructional strategies and education \& teaching methods while vigorously improving professional skills and enhancing learning capacities of teachers, being good at exploring for humanistic quality in college English teaching, continuously summarizing lessons and experiences and adhering to the principles of "we do everything for our students", so as to achieve the goal of promoting integrated development of students' comprehensive quality. Additionally, we should discuss how to promote college students to benefit in academic works and in spirits instead of simply pursuing for passing CET Band 4 or CET Band 6.

(II) Continuously improve the model of teaching and adopt flexible education and teaching methods

First, teachers in universities and colleges should take full advantage of advanced new media and electronic techniques to vigorously explore potential capabilities of E-learning and lay emphasis on advantages of new media. For instance, teachers and students can chat, send messages or emails online in daily life, or chat, write blogs or post messages on BBS in English. Above recommendations can yet be regarded as effective and beneficial practices.

Second, there is a folk adage in China "To teach a student, you must find a good way to teach and the good way is not set”. Teachers in universities and colleges must get quite familiar with the development history of college English teaching as well as various modes in English teaching and respective use range and characteristics of such modes. Additionally, suitable modes and methods should be implemented according to actual conditions of college students. In particular, teaching patterns liked by most college students should be selected to make college students love to study, willing to learn and succeed in special fields of study.

Third, teachers in universities and colleges should fully excavate humanistic education factors in college English teaching and correctly and effectively guide college students, so as to improve humanistic quality of college students. In a word, teachers' notion transformations and specific teaching by precept and example influence to a large extent flexible application and improvement of means and methods for humanistic spirit in English teaching. 
(III) Set up correct curriculum views and promote overall development of students

From the perspective of humanistic quality cultivation in colleges and universities, the college English course is not simply a language course. Teachers teach students knowledge and make students to develop their capabilities and master knowledge. More importantly, deeper values lie in the promotion of students' moral, intellectual and physical development. Hence, the ultimate goal of college English courses should not be simply to deal with tests or get a diploma. Moreover, it is also not the final goal to learn to communicate in English. After all, these items should be achieved according to the surface structure of college English courses. If students fail to achieve such extremely simple goals, how we can implement humanistic education?

Therefore, we should not lay much emphasis on teaching programs, courses, textbooks or other dominant factors in the college English education and teaching process. Instead, we should attach more importance to some factors that are neglected by us, i.e. recessive factors. In other words, some factors beyond courses, textbooks and teaching programs should be used to make college students to be good at seizing opportunities and utilizing what they have learnt to communicate and exchange while promoting college students to accept dominant curriculum learning, making college students to learn more practical and valuable things and virtually improving humanistic quality of college students.

(IV) Set up correct goals and philosophies for humanistic spirit education in college English teaching

Based on the current situation of some colleges and universities weak in consciousness of humanity and neglecting humanistic education, we must fully realize different levels of teaching goal, ravel out correct goals and philosophies for humanistic education in college English teaching, have a correct understanding of humanistic education from the strategic perspective of "cultivate perfect men", and take "cultivate perfect men" as the supreme goal of education. Therefore, we should achieve mutual promotion and common progress of knowledge and competence (including continuous improvement to comprehensive English quality and overall quality) while implementing humanistic education and overall planning in college English teaching, so as to serve the society and keep pace with rapid development of the society instead of simply pursuing for a diploma. If we blindly lay much emphasis on quick success or put the cart before the horse, students will generally fail to pass the examination. Even through they pass the examination by chance, they will loose opportunities for higher study and research due to restrictions of ultimate learning goal, let alone their motivation and enthusiasm. Then, overall and harmonious development of students will be affected. More seriously, it is difficult to achieve academic requirements of higher education for students.

\section{Conclusions}

In conclusion, integration of humanistic education into English teaching in colleges and universities is beneficial for giving full play to potentials and personalities of college students thereby to have strong English knowledge and language skills and adapt to requirements of new times for foreign language talents. At the same time, such integration can greatly promote autonomic learning of college students and improve the efficiency of education, making college students to have higher culture and stronger self-awareness and promoting college students' development toward the integration of knowledge, competence and morality.

\section{Acknowledgments}

This paper is the achievement of "research on ESP teaching mode and method in higher vocational education", a special subject of the " $12^{\text {th }}$ five-year plan" foreign language teaching reform in colleges and universities held by Liaoning Association of Higher Education. Project Leader: Wang Xin; Project No.: WYYB12056 


\section{References}

[1] Yu Liming, A Perspective on Functions of Human Education in College Foreign Language Teaching [J], Journal of Social Science of Jiamusi University;

[2] Du Ruiqing, Pioneering and Innovation of Culture Self Learning [A], Zhang Houchen, Abstract of Famous Speeches of Foreign Language Celebrities [C], Beijing, Foreign Language Teaching \& Research Press;

[3] Wang Dongfeng, Cultural Difference and Reader's Response [M], Culture and Translation, Beijing, China Foreign Translation Press, 2003;

[4] Deng Yanchang and Liu Runqing, Language and Culture [M], Beijing, Foreign Language Teaching \& Research Press, 2006;

[5] Wang Naimin, Factors Restricting College English Teaching Effects and Relevant Countermeasures [J], Foreign Language World, 2002;

[6] Zhao Weixin, Human Spirit Foster for University Students in Twenty-one Century [J], Journal of Suihua Teachers College, 2002;

[7]Zhang Lei, Reflections on Humanistic Education in Universities [J], Fudan Education Forum, 2008;

[8] Peng Guangmang, Cultural Quality Education and Entrepreneurial Ability Cultivation [J], Higher Agricultural Education, 2002;

[9] Kramsch C, Context and Culture in Language Teaching [M], Shanghai, Shanghai Foreign Language Education Press, 2010;

[10] Liu Xudong, Humanistic Spirit and Modern Course Design, Journal of Northwest Normal University (Social Sciences), 1998. 